Shou W., Wang J., Wu P., Wang X. and Song Y. (2017). "Application of Lean Production With VSM to the Blasting and Coating Industry.” In: LC3 2017 Volume II - Proceedings of the 25th Annual Conference of the International Group for Lean Construction (IGLC), Walsh, K., Sacks, R., Brilakis, I. (eds.), Heraklion, Greece, pp. 217-224. DOI: https://doi.org/10.24928/2017/0308

\title{
APPLICATION OF LEAN PRODUCTION WITH VALUE STREAM MAPPING TO THE BLASTING AND COATING INDUSTRY
}

\author{
Wenchi Shou ${ }^{1}$, Jun Wang ${ }^{2}$, Peng $\mathrm{Wu}^{3}$, Xiangyu Wang ${ }^{4}$ and Yongze Song ${ }^{5}$
}

\begin{abstract}
Lean production involves a variety of principles and techniques, all of which aim to eliminate waste and non-value-added activities at every production or service process. To stay competitive, many Australian owners in the blasting and coating industry have sought to improve their production process productivity and human performance. The purpose of this study is to evaluate the feasibility of existing lean principles by using Value Stream Mapping (VSM) in the blasting and coating industry. A real case is selected as a model, both current and future states of shop-floor production scenarios are discussed using value stream concepts. This is analysed along with calculations of cycle time, work-in-process inventory, and waiting time. A framework of lean improvement is proposed which includes: (1) waste elimination by using techniques of standardisation, supermarket, and pull scheduling system; (2) workforce involvement; and (3) client integration. The results showed that the product delivery rates could be significantly increased through lean implementation.
\end{abstract}

Keywords: lean production, value stream mapping (VSM), blasting and coating industry, production management, pull scheduling

\section{INTRODUCTION}

Lean production has been applied to many businesses that wish to remain their competitiveness in an increasingly global market. Lean production is designed to eliminate all activities that do not add value throughout the production process (Womack and Jones 2010). Originally, it was developed from car manufacturing in Japan, but the main lean techniques have been applied to a wide variety of other processes in manufacturing, healthcare, construction and service.

Despite the diversity of applications in different production sectors throughout the world, the lean production principles lag within the blasting and coating industry, partly because of particular difficulties of implementation in these types of processes. One of the characteristics of these operations is that product mix grows as the material moves through the process, creating a wide variety of in-process production schedules, making it difficult to apply some traditional lean concepts. Moreover, despite the simple production steps, production planning and control is decided based on manager's experience. No formal

1 Ph.D. student, Australasian Joint Research Center for BIM, Curtin Univ., Perth, Australia, wenchi.shou@postgrad.curtin.edu.au

2 Ph.D. student, Australasian Joint Research Center for BIM, Curtin Univ., Perth, Australia, jun.wang15@postgrad.curtin.edu.au

3 Senior Lecture, Australasian Joint Research Center for BIM, Curtin Univ., Perth, Australia, peng.wu@curtin.edu

4 Professor, Australasian Joint Research Center for BIM, Curtin Univ., Perth, Australia, xiangyu.wang@curtin.edu.au

5 Ph.D. student, Australasian Joint Research Center for BIM, Curtin Univ., Perth, Australia, yongze.song@postgrad.curtin.edu.au 
documents are available to track the production progress. Due to the unique features faced in this kind of industry environment, lean production application is a challenge to be adapted.

The purpose of this piece of research is to evaluate the feasibility of existing lean principles by using Value Stream Mapping (VSM) in the blasting and coating industry. VSM is the most efficient tool of lean thinking and has proved its value of increasing process visibility (transparency) (Klotz et al. 2008) and reducing lead time (Tyagi et al. 2015) in many sectors (Shou et al. 2017). VSM is used as the primary tool to identify waste in the process, developing a current map; subsequently, a future map with the proposed improvements is generated, as well as the working plans, used to monitor the implementation project (Rother and Shook 2003).

\section{RESEARCH METHODS}

To analyze the applicability of lean methodologies in blasting and coating workshop, this research employed the case study method (Yin, 2013). The case study can suitably be used for theory testing and refinement, which allows the study of production management and organizational phenomena in their actual context. In this research, the information for case analysis was collected from semi-structured interviews and direct observation in three days. One complete work order was selected to study the applicability.

\section{CASE STUDY}

The case study was conducted in a steel blasting and coating workshop. The coating company communicates with their clients and upfront steel fabrication companies by telephone and email for orders, and buys painting materials used in the processes according to the blasting and coating requirement provided by the clients. Once the fabricated steel has been loaded on the site, the production in the workshop is responsible for the quality of customized blasting and coating work. The production is daily planned but, relying on the production manager's experience by referring to deadlines and urgencies required by clients. The production has no planning for the progress for clients.

There are three main parts of the production processes in the workshop: blasting, coating, and delivery. All the blasting is conducted in the one blasting chamber. The client orders are divided into several batches because of the chamber space limitation. Batches are lifted from the storage area and loaded on the trolleys before they are pushed into the blasting chamber and be blasted sequentially. Then the blasted steels are placed at the coating area by crane drivers. However, the coating work doesn't follow the same batch size as in the blasting process. The painters start the coating work once all the batches have the same coating requirement have been placed on the site. Moreover, the delivery work can only start once all the batches in one order have been completed. Therefore, the work batches have a huge deviation in the processes.

\subsection{CURRENT STATE MAP}

After carefully collecting the production information, the map of the current process was developed. Figure 1 shows the current state map. The value stream for a typical blasting and coating was mapped in detail, which includes flows of information and material.

1. Information flow: 
- The straight arrows represent oral information between processes. The production manager and the supervisor are responsible for every process; so they have a role to inform and approve each production process.

- The broken arrows represent electronic information. Clients make the orders and check the production quality and progress by telephone.

2. Material flow:

- The squares represent each operation with data such as the number of workers, the cycle time (CT), processing time (PT), work in process (WIP), batch size, and waiting time (WT) in each process.

- The crane represents the steel transportation, turnover or loading carried by crane drivers.

- The thick dark arrows represent the in-process material that is pushed to a production process to the next one.

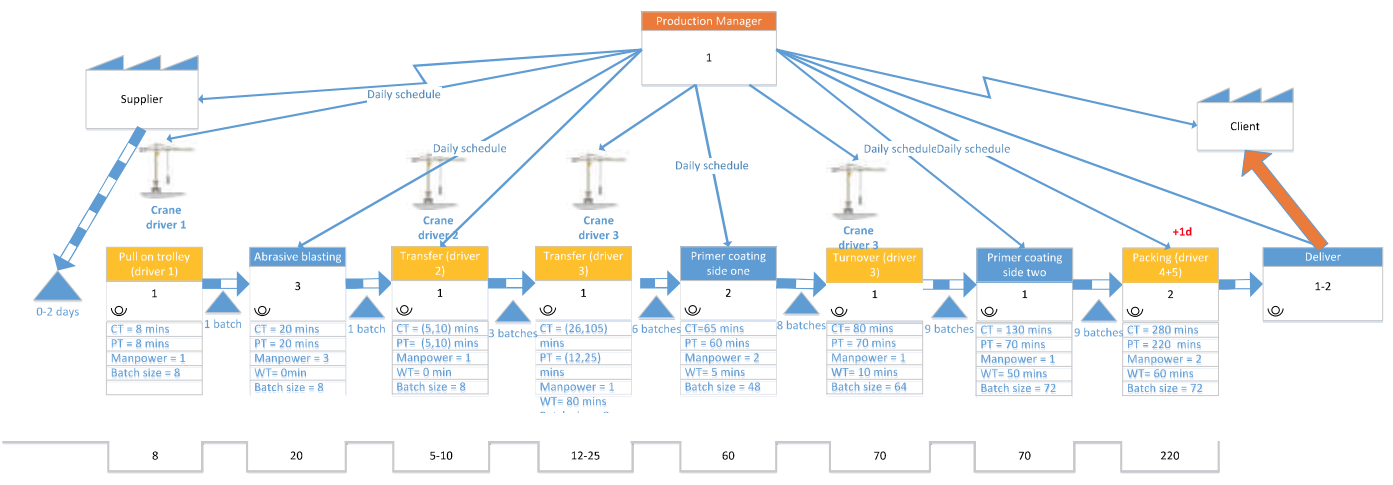

Figure 1 Current state map

In the current process map, the need for waiting resulted from the changes of batch size is shown explicitly in Figure 1. Another important waste shown in the process is the accumulation of WIP. This waste is derived from the fact that the overall production is planned and pursued without consideration of the impact of the labour availability and schedule coordination.

As shown in Table 1, it is noted that the total duration of the selected case is 949 minutes, but the total VAT only account for 290 minutes $(30.56 \%)$. The non-value adding time (NVAT) but necessary work is 471 minutes (49.63\%), while the waste is $19.81 \%$.

Table 1: performance analysis

\begin{tabular}{ccc}
\hline Metrics & Percentage & Amount of time (mins) \\
\hline VAT & $30.56 \%$ & 290 \\
NVAT but & $49.63 \%$ & 471 \\
necessary & & \\
Waste & $19.81 \%$ & 188 \\
\hline
\end{tabular}

Besides, the waste was analysed from the perspective of production line as well. There are 8 primer coating orders and 6 three coating orders have been processed in the three 
days. However, the number of orders have been delivered is 4 and 1, respectively. Table 2 lists the delivery rate for the orders produced in the three days' observation (delivery rate= the number of material have been delivered / the number of material have been processed). If the quantity of WIP required would be reduced, the delivery rate could also be improved.

Table 2: delivery rate in the data collection period

\begin{tabular}{cc}
\hline $\begin{array}{c}\text { Types of } \\
\text { production }\end{array}$ & Delivery rate \\
\hline Primer & $50 \%$ \\
Third coating & $16.67 \%$ \\
\hline
\end{tabular}

Table 3: Reasons analysis

\begin{tabular}{ccc}
\hline Reasons of waste & Percentage & Amount of time (mins) \\
\hline Lack of planning & $37.77 \%$ & 71 \\
Push schedule & $36.57 \%$ & 65 \\
Worker's low & $27.66 \%$ & 52 \\
productivity & & \\
\hline
\end{tabular}

As shown in Table 3, one apparent cause of high WIP is that lack of planning. In the daily work plan, crane drivers and painters are assigned to orders with high priority. However, they reported that the work assignment tends to randomly direct their efforts to those steels in which have been blasted and placed on site. They get another oral work assignment once they have done the current work. It is hard to recognize the priorities without any formal progress record of the work in the workshop.

Push scheduling is another cause of high WIP. Waiting time in production process increased because of the push production progress. Orders with work left (for example, waiting for being coated, turned over, or packed for delivery) are simply not completed due to the push work carried out by limited workforce, thus, remaining as WIP.

Another important reason of high WIP has been observed is the low productivity of the crane driver. The transfer and placement work conducted by crane driver 3 didn't follow the same batch size. The increased transfer time because of the reduced batch size (the reduced number of steels that have been transferred at one time) raised the WIP.

In summary, the existing process exhibited various forms of waste, different batch sizes, low success delivery rate and high levels of WIP.

\subsection{FUTURE STATE MAP}

Looking at the current state map for blasting and coating work several things stand out: (a) significant waiting time, (b) the low success delivery rate, and (c) each process producing to its own schedule, large WIP caused by in-process workforce and schedule constraints. WIP and low delivery rate may be viewed as two related issues since the more the WIP, the longer any processed order must wait for its turn of next process and thus, the lower the delivery rate. In creating the ideal future state map, this research tries to identify solutions to drive both of these down while looking at the schedule across the 
entire value stream. There are eight guidelines to introduce lean thinking into a value stream, according to Rother and Shook (2003). Applying them to this case study, we proposed the following improvement framework to the production processes (as shown in Figure 2). The wastes have been identified are listed in the framework. Lean practices have been proposed from three perspectives: waste elimination, workforce involvement, and client integration. Due to the limited space, the improvement strategies of workforce involvement and client integration will not be addressed further in this paper. The three lean measures were discussed in detail in the following sections.

\begin{tabular}{|c|c|c|c|}
\hline \multicolumn{4}{|c|}{$\begin{array}{l}\text { Lean goals } \\
\text { Increase productivity and improve quality to increase customer value \& profit }\end{array}$} \\
\hline \multicolumn{4}{|c|}{ Waste identified } \\
\hline Push scheduling & \multicolumn{3}{|c|}{$\begin{array}{l}\text { Delay caused by the successor paint work } \\
\text { Delay caused by the site preparation } \\
\text { Delay caused by paint preparation } \\
\text { Delay caused by paint dry time } \\
\text { Delay caused by quality check work }\end{array}$} \\
\hline Lack of planning & \multicolumn{3}{|c|}{$\begin{array}{l}\text { Delay caused by painter unavailable (workforce constraints) } \\
\text { Delay caused by crane driver unavailable (workforce constraints) }\end{array}$} \\
\hline $\begin{array}{l}\text { Workers' low } \\
\text { productivity }\end{array}$ & \multicolumn{3}{|c|}{ Delay caused by driver's low productivity } \\
\hline \multicolumn{4}{|c|}{ Lean solutions } \\
\hline \multicolumn{2}{|c|}{ Elimination of waste } & $\begin{array}{l}\text { Creative involvement of the } \\
\text { workforce }\end{array}$ & Integration of client \\
\hline \multicolumn{4}{|c|}{ Lean practices } \\
\hline $\begin{array}{l}\text { - } \text { Supermarke } \\
\text { - Standard op } \\
\text { - Pull schedul }\end{array}$ & $\begin{array}{l}\text { t } \\
\text { erations } \\
\text { ing system }\end{array}$ & $\begin{array}{l}\text { - Team-based problem solving } \\
\text { - Worker-driven kaizen } \\
\text { - Training }\end{array}$ & $\begin{array}{l}\text { - } \quad \text { JIT deliveries } \\
\text { - } \quad \text { Client } \\
\text { rationalisation }\end{array}$ \\
\hline
\end{tabular}

Figure 2: Framework of lean improvement

\section{Supermarket}

Before the coating process, the production in the workflow can be continuous since the materials move in the same batch size. At the coating, however, the blasted steel can merge and move through one of many possible routines based on the required coating standard and workers' experience. Different cycle time and batch size of the coating work, make it difficult to introduce continuous flow in this process. Meanwhile, the subsequent processes of turnover, second side of coating and delivery are restricted to different schedules depending on product shape, workforce availability and orders coordination. Therefore, it is unrealistic to join these processes to obtain a continuous flow. The focus at the end of 
transfer process should be on developing a system to enable pull by the customer, rather than continuous flow.

A "supermarket" is a buffer located at the process where continuous flow is not available. The recommendation is that steel produced to a supermarket (store at the coating area) and whenever the supermarket inventory is higher than a certain level this would trigger the coating process.

The introduction of supermarkets that are controlled by a Kanban system forces the entire coating to pace every process to the speed of the bottleneck (to match the coating pace with blasting time), which as the current state map indicated that it is located between the blasting and coating. Thus the coating begins to take on the characteristics of a production line where batches start to flow rather than stop and start.

The second supermarket is recommended to stabilize the second side of coating process for the turned over material. The inventory after turned over and before second side of coating is large. This is because the painters start the second side of coating after all the batches in one order have been turned over. It is necessary to set up a supermarket to accommodate progress coordination (that is coordinate the work of turnover and second side coating). Again, a Kanban pull system can be used to regulate second side of coating start time.

The Kanban at the supermarkets follow the standard rules of a pull system. For example, the painter is allowed to process the other work in the workshop as long as there is an empty spot in the supermarket for the transferred steel. By definition, if the supermarket is less than its capacity then this means that the steel batches does not need painting.

2. Standard operation

Standard operation procedures are designed to reduce waste in scheduling activities. Work standards show what, where, when, who and how tasks should be carried out to ensure customer satisfaction.

Currently, the steel being processed in workshop displaying a unique functionality, configuration, and size. The production processes of coating, turnover, etc. are operated based on the operators' skills and experience accordingly. Therefore, the purpose of this method is to use rigorous process standardization of difference coating system to reduce variation, thereby creating both flexibility and predictable outcomes.

Standard operation routine sheets could be used to show the time relationship between the workers and the production system. The information required to create the routine sheet are the time it takes a painter to finish one side painting, the paint dry time of the different paint standards, etc. The processing data can summarize from (1) statistic data analysis: manual data record and summary; (2) feedback from worker based on their experience.

The standard processing procedure and time framework of primer, second, and third coating system is formatted by reducing the interval time between two sides painting, the interval time from a finished round of coating to next round of coating, and the waiting time before delivery.

\section{Pull scheduling system}

A pull system is one in which the control of information flows in the opposite direction to the material flow. To eliminate the waste caused by the conflict of workforce in the production process and increase the transparency of the production schedule, future state improvement develops a pull scheduling system to replace the dictated schedule plan created by the production manager. The push-driven sequence of work is replaced with a 
sequence designed by the availability of stable production information. The production manager works with estimator assessing the maturity of the order, and releases work order to the schedule according to a continuously updated list of information. Ideally, the work order is not introduced into the production process unless all the conditions for its completion have been completely fulfilled (e.g. the material arrival and delivery time is confirmed respectively, the procurement of paint has done, and the paint is stored on site). A daily and weekly production schedule will be created based on the information provided. Pull scheduling with the input of customer orders plus ongoing work in the workshop, which creates a set of prioritized orders.

Pull priority (human resource assignment and start time) setting:

- Level 1: Delivery at the same day

- Level 2: Delivery at the next day

- Level 3: Delivery at the third day

The pull scheduling system has two significant potential benefits:

- The waste of waiting caused by human resource conflict is essentially eliminated. Production work in process are not executed according to the daily work job assigned from production manager or randomly assigned in the workshop, but are instead always performed according to the priority setting.

- WIP is controlled. The desired level can be determined roughly by multiplying (1the required delivery rate (on the overall production schedule)) by the number of the daily order be processed.

In practice, each batch/order requires a unique sequence of production, each with varying durations and often with different procedures. The rate of introduction of "mature" order into the system depends on the arrival time and the clients' decision making and may therefore also be irregular. These sources of variation can be coped with in some ways: (1) by planning buffers of stable work; (2) with flexible labor resource strategies. The sequence of production can be prioritized for release not only regarding delivery time but also regarding the probability of coating work are likely to be reached considering other factors (e.g. weather and the dry time required for different paint thickness). In this way, orders with less than $100 \%$ production information can be released when necessary. Time buffer between procedures should be monitored and reduced to a minimum necessary to avoid unacceptable extension of lead time.

\section{RESULTS OF LEAN PRODUCTION}

The implementation of the future state is ongoing in the case study company. A three months kaizen plan was formulated to break the application into steps and to provide a time frame for improvements. The objectives of each phase were outlined as follows:

- Standardize work process with the assistant of standard operation routine sheets and educate the site workers to eliminate handover problems;

- Implement Kanban to raise the schedule control;

- Reduce waiting time between processes to the level shown on the future state map;

- Establish supermarket-based pull flow in the whole process with the consideration of standardized production processes;

- Involve client in the process to have the just in time levels of both input and output 
The expected results for the industry after this piece of research and analysis of the application of lean production techniques to produce blasting and coating can be deduced. The analysis of production data from the workshop that adopted the pull schedule showed that the duration of production had a slight reduction, but that the delivery rates have increased dramatically. The delivery rate during the same measurement period has increased to $76.5 \%, 54 \%$ of the primer and third coating system respectively.

\section{CONCLUSION}

The applicability of lean production techniques in the blasting and coating industry has been presented, with the aim of improving the production process efficiency. First, VSM has been used as the primary tool to identify process wastes, and the present and future maps have been developed, as well as an analysis of the estimated results of the application in the workshop. Second, as an example of the application of the methodology, a plan has been developed to implement it in three months, structured in several steps.

The key issues derived from the proposed methodology, those that can be considerably improved by its application, are the inventory reduction, the appropriate schedule management, and elimination of the waiting time. These problems, which were presented in this case study can be considered as the key for the extrapolation of the proposed methodology and the expected results to other process industries.

It should be noted that due to the rising recognition of offsite construction and prefabrication in the construction industry, this study provides useful insights into the use of VSM in determining the scheduling of offsite construction and prefabrication due to its repetitive nature. It is recommended that future studies should focus on generalizing the use of VSM in the construction industry by also considering non-repetitive and non-typical activities.

\section{REFERENCE}

Klotz, L., Horman, M., Bi, H. H. \& Bechtel, J. (2008) The impact of process mapping on transparency. International Journal of Productivity and Performance Management, 57(8), 623-636.

Rother, M. \& Shook, J. (2003) Learning to see: value stream mapping to add value and eliminate muda, Lean Enterprise Institute.

Tyagi, S., Choudhary, A., Cai, X. \& Yang, K. (2015) Value stream mapping to reduce the lead-time of a product development process. International Journal of Production Economics, 160, 202-212.

Wenchi, S., Wang, J., Wang, X. \& Chong, H.-Y. (2015) An application of value stream mapping for turnaround maintenance in oil and gas industry: Case study and lessions learned, Procs 31st Annual ARCOM Conference. Lincoln, UK, 7-9 September, 2015. Association of Researchers in Construction Management.

Wenchi, S., Wang, J., Wu, P., Wang, X. \& Chong, H.-Y. (2017) A cross-sector review on the use of Value Stream Mapping. International Journal of Production Research

Womack, J. P. \& Jones, D. T. (2010) Lean thinking: banish waste and create wealth in your corporation, Simon and Schuster.

Yin, R. K. (2013) Case study research: Design and methods, Sage publications. 